BNL- 18395

CRISP 73-19

$\mathrm{NG}-269$

\author{
BROOKHAVEN NATIONAL LABORATORY \\ Assoctated Untversities, Inc. \\ Upton, L.I., N.Y.
}

ACCELERATOR DEPARTMENT

Informal Repo:t

STOICHASTIC COOLING IN GENERAL AND ITS APPLICATION TO

p STORAGE IN PARTICULAR

R. B. Palmer

October 15,1973

NOT I C E

This report was prepared as an account of work sponsored by the United States Government. Neither the United States nor the United States Atomic Energy ComIssion, nor any of thelr employees, nor any of thelr contractors, subcontractors or their employees, makes any warranty, express or 1mplied, or assumes any legal liability or responsibility for the accuracy, completeness or usefulness of any information, apparatus, product or precess disclosed, or represents that its use would not infringe privately owned rights. 
R. B. ralmer

Stolchastic cooling in general and its application to $p$ storage in particular

I present here some basic formulae for stolchastic cooling. The formulae are not exact but suffice to get order of magnitude results.

\section{Simplest Calculation}

Consider a ring of some large circumference $S$ containing $\mathrm{N}_{\mathrm{T}}$ particles traveling near the velocity of 11ght. Now suppose that we have some scheme that detects the mean lateral position $(\bar{y})$ of an element of the beam at a "plck up station" of length $\ell$. The number of particles in that element we call N.

$$
N=\frac{\ell}{S} N_{T}
$$

If the signals corresponding to such displacements $(\bar{y})$ are amplified and used to correct these displacements at a "corrector station" at a point further round the ring, then the mean squared displacement $\sigma^{2}$ will be slowly reduced. First we assume:

1) negligible noise in the amplifier;

2) adequate band width, Ie band width $F$ $F \geq 2 \pi B c / l \quad$ cycles/ $s \in c$ where $B C$ is the velocity of the particles; 

3) particle transit time between pickup and corrector station constant to a time small compared with $\ell / B C$.
4) transit time for a complete rotation around the machine must have random fluctuations large compared with $\ell / B C$

Given these conditions we can now calculate what might be called the Ideal stolchastic cooling rate. Let $y_{1}$ be the displacement of the 1th particle. The mean square displacement will be

$$
\left.\sigma^{2}=\underset{N_{T}}{(\Sigma} y_{i}^{2}\right) / N_{T}
$$

The mean positions detected

$$
\bar{y}=\left(\begin{array}{cc}
\Sigma & y_{1}
\end{array}\right) / N
$$

w11l themselves have a distribution and will have a mean square value

$$
\bar{y}^{2}>=\sigma^{2} / \mathrm{N}
$$

If the signals corresponding to these mean positions are amplified by a factor (a) and used to correct the trajectorles, then the y position of each particle after correction will be $y_{1}-a \bar{y}$ and the resultant mean square displacement $g^{\prime}$ w111 be given by:

$$
\begin{aligned}
\left(\sigma^{\prime}\right)^{2} & =\sum_{i !} \quad\left(y_{1}-a \bar{y}\right)^{2} / N \\
& \left.=\underset{i}{i} \quad\left(y_{1}^{2}\right)-\underset{N}{2 a \bar{r} y_{1}}+N a^{2} \bar{y}\right) / N
\end{aligned}
$$




$$
\left(\sigma^{\prime}\right)^{2}=\sigma^{2}-2 a y^{2}+a^{2} y^{2}
$$

On average $\quad\left\langle\left(\sigma^{\prime}\right)^{2}>-\sigma^{2}-\left(2 a-a^{2}\right)<\bar{y}^{2}\right\rangle$

$$
=a^{2}\left(1-\frac{2 a-a^{2}}{N}\right)
$$

1e on average the mean square deviation is reduced by the fraction

$$
f=\frac{2 a-a^{2}}{N}
$$

Clearly maximum cooling is obtalned with $a=1$ and

$$
f_{\max }=\frac{1}{N}
$$

If, as at the ISR, $N_{T}=410^{14}, 2=3 \mathrm{~cm}, F=2 \mathrm{cHz}$, then $\mathrm{N}=10^{10}$ and $\mathrm{E}=$ $10^{-10}$. The time to reduce $a^{2}$ to about $1 / \mathrm{e}$ is then $10^{10} \times 2$ usec $=6$ hours. The CERN expected time i is 24 hours but 10 turns out that at CERN our assumtion (3) is not satisfied, 1.e. there is stgniflcant transit time spread between plck-tp and corrector stations.

\section{Consider transit cime spread between $p 1 c k-40$ and corrector}

If on average a fraction $c$ of the particies in the length $l$ at the plck-up station remain in a length $l$ at the correction station then equation (6) must be modified (see Append1x I):

$$
f=\frac{2 a c-a^{2}}{N}
$$


Maximum reduction is obtained for $a=\varepsilon$ and for this value

$$
f_{\max }=\frac{\varepsilon^{2}}{N}
$$

At $\operatorname{CERN} \varepsilon=1 / 2$ and thus the cooling tiae $\tau$ is increased to $=24$ hours. This agrees with the CERN calculated number as reported in Months forefgn travel report.

At CERN the transit time fluctuations for a complete cycle are very large compared with $\mathrm{Q} / \mathrm{Sc}$ and thus no correction is needed for this. Only in a mactine near transition or a machlne with very small momentum spread would this become a problem. If then the fluctuations in transit time are $\Delta t$ and we define $\delta=\frac{l}{\beta c \Delta t}$ then we find that the maximum cooling fraction is given by

$$
f_{\max }=\frac{\varepsilon^{2}(1-2 \delta)}{N}
$$

Since $\delta$ is in general negligible we will not consider this effect further.

\section{Constderation of Notse}

At CERN the noise is less than $10 \%$ of the pick-up signal and has a negligible effect. The situation is very different, however, in the case of a $\bar{p}$ storage ring. In a $\bar{p}$ storage ring the total number of particles $N_{T}$ is unlikely to be more than $10^{12}$ finally and not more than $10^{7}$ would be made per AGS pulse. If these were in a storage ring like the ISR the number $N$ in a length of $3 \mathrm{~cm}$ irould be only 200 . Under such circumstances the cooling time 1s only $400 \mu \mathrm{sec} /$ No1se in the plck-up system however makes this unatcalnable. 
Let $b$ be the solse quoted in terms of the apparent RMS $y$ positior of one particle in $\mathrm{cm}$ 's. At $\mathrm{CERN} b=10^{4} \mathrm{~cm}$, le unless we have more thas $10^{4}$ particles one could not find where they were to better than $1=\mathrm{m}$ !

Given this definition of b we get Instead of equation $(\varepsilon)$

$$
=\frac{2 a \varepsilon-a^{2}}{N}-\frac{a^{2} b^{2}}{N^{2} \sigma^{2}}
$$

The maximum cooling is obtained for

$$
a=\varepsilon /\left(1+b^{2} / \mathrm{No}^{2}\right)
$$

If $b$ is large then ti,e reduction factor is given by:

$$
f=\frac{a^{2} c^{2}}{b^{2}}
$$

and this is not a function of $\mathrm{N}$ !

If we again uge the CERN aignal to nolse ratio we can then derive. this maximum cooling rate.

$$
\frac{b}{\sigma}=\frac{\text { nolge }}{\text { signal }} \sqrt{\mathrm{N}}=\frac{1}{10} \cdot 10^{5}=10^{4}
$$

then $\quad=10^{-8} \cdot \varepsilon^{2}$

$$
\text { for } \varepsilon=1 \quad \mathrm{f}=10^{-6} \quad T=2 \text { usec } \times 10^{8}=200 \mathrm{sec} \text {. }
$$


Two ways present themselves for further improving this rate:

(1) lower the noise.

(2) increase the rate of corrections per second.

The former can possibly be achieved when it is noted that the band width is not specified and need not be nearly as larje as that used at CERN. Theoretically this does not lower the nolse ratio since the plate lengths have to be lengthened as the band width is lowered. Despite this, the freedom of choosing the band width could probably allow lower noise amplifiers.

The second solution suggests the use of a small ring. Although the number of particles per untt length will be larger this does not affect the rate. The increased number of corrections per sec, however, will be directly useful. For 1nstance, if we capture $\bar{p}$ 's at $3 \mathrm{GeV}$ we can have a ring $1 / 10$ the size of the ISR and get a cooling time of only 20 seconds. Ihis consideration must, however, be weighed against the smaller total phase space caparity of the smaller ring and thus the smaller number of $\bar{p}$ 's that can be captured prior to cooling.

We have shown that the cooling for a $\bar{p}$ ring is noise limited yet, when figures taken from CERN are used and the best gain selected, then cooling times as short as $20 \mathrm{sec}$ are still possible.

I conclude then that Stoichastic cooling would allow the collection, cooling and stacking of $\bar{p}$ 's from some quite large number of AGS pulses. 


\section{Consideration of Transit Time Fluctuations between plck up and Corrector}

\section{Stations.}

We will consider the sample of particles $\left(N_{0}\right)$ between the pick up electrodes and the sample of particles $\left(\mathrm{N}_{4}\right)$ that 1 le between the corrector plates. at a later time when the correction signal derived from the first sample is applied to the corrector plates. Ideally these two samples are Identical and the time delay is obviously set to maximize the number of particles that are present in both samples. let us now subdivide each of the two samples dertved above ( $\mathrm{N}_{0}$ and $\mathrm{N}_{4}$ ) into subsets:

Let $\mathrm{N}_{1}$ be the number of particles found in both samples $\mathrm{N}_{0}$ and $\mathrm{N}_{4}$.

Let $N_{2}$ be thcse in the sample $N_{0}$ that are not in $N_{1}: N_{2}=N_{0}-N_{7}$

Let $N_{3}$ be those in the sample $N_{4}$ that are not in $N_{1}: N_{3}=N_{4}-N_{1}$

We $k 111$ denote sums over the samples $N_{k}$ by $\Sigma_{k}$ and define $s_{k}=\sum_{k} y_{1}$.

The correction signal is now given by the amplification factor(a) times the mean position of the particles between the pick up electrodes; 1.e. correction signal $=a s_{0} / N_{0}=a\left(s_{1}+s_{2}\right) / N_{0}$. This signal is then used to correct the positions of all the particles between the corrector plates. Positions $\left(y_{1}\right)$ of the particles 1 in the sample $N_{4}$ are then changed to $y_{1}-a\left(s_{1}+s_{2}\right) / N_{0}$. The mean square deviation after correction $\left(0^{\prime}\right)^{2}$ is then given by: 


$$
\begin{aligned}
\left(\sigma^{\prime}\right)^{2} & =\sum_{4}\left\{y_{i}-a\left(s_{1}+s_{2}\right) / N_{0}\right\}^{2} / N_{4} \\
= & \frac{4 y_{i}^{2}}{N_{4}}-\frac{2 a\left(S_{1}+s_{2}\right)}{N_{0} N_{4}} \sum_{4} y_{i}+\frac{a^{2}\left(s_{1}+S_{2}\right)^{2}}{N_{0} 2}
\end{aligned}
$$

Now $\sum_{4} y_{1}^{2} / \mathrm{N}_{4}=\sigma^{2}, \sum_{4}^{\Sigma} \mathrm{y}_{1}=\mathrm{s}_{4}=\mathrm{s}_{1}+\mathrm{s}_{3}$

$$
\left(\sigma^{\prime}\right)^{2}=\sigma^{2}-\frac{2 a\left(s_{1}+s_{2}\right)\left(s_{1}+s_{3}\right)}{N_{0} N_{4}}+\frac{a^{2}\left(s_{1}+s_{2}\right)^{2}}{N_{0}^{2}}
$$

Now we must consider what the average or expectation values of the sums $S$ are when averaged over some number of cycles. The mean square expectation value of any sum $s_{k}$ is given by

$$
\left\langle\mathrm{s}_{\mathrm{k}}^{2}\right\rangle=\left\langle\left(\overline{\mathrm{y}}_{\mathrm{k}} \mathrm{N}_{\mathrm{k}}\right)^{2}\right\rangle=\sigma^{2} \mathrm{~N}_{\mathrm{k}}
$$

However the expectation vaiue of the product of two uncorrelated samples, e.g. $\mathrm{N}_{1}$ and $\mathrm{N}_{2}$, is zero

$$
\left\langle s_{1} \cdot s_{2}\right\rangle=0
$$

Thus

$$
\left\langle\left(\sigma^{\prime}\right)^{2}\right\rangle=\sigma^{2}-\frac{2 a \sigma^{2} N_{1}}{N_{0} N_{4}}+\frac{a^{2}\left(\sigma^{2} N_{1}+\sigma^{2} N_{2}\right)}{N_{0}^{2}}
$$


We now note that $\mathrm{N}_{4} \simeq \mathrm{N}_{0}$, and define $\varepsilon$ by $\mathrm{N}_{1}=\varepsilon \mathrm{N}_{0}$. In the ideal situation of no transit time fluctuations $\varepsilon=1$. As the fluctuations become significant so $E$ is reduced. At the CERN $\operatorname{ISR} \varepsilon \simeq 0.5$.

So using this definition of $E$ we obtain.

$$
\left\langle\left(\sigma^{\prime}\right)\right\rangle=\sigma^{2} \quad\left\{1-\frac{2 a \varepsilon+a^{2}}{N_{0}}\right\}
$$

or if

$$
<\left(\sigma^{\prime}\right)>=\sigma^{2}\{3-\mathrm{f}\}
$$

$$
f=\frac{2 a \varepsilon-a^{2}}{N}
$$

